\author{
RESEARCH ARTICLE \\ 10.1029/2018JC014392 \\ Key Points: \\ - An adaptive sampling strategy \\ allows for fine-scale observations of \\ biophysical vertical processes inside \\ a cyclonic mesoscale structure \\ - Multipolar patterns of intense \\ downward and upward velocities \\ (from adiabatic QG omega-equation) \\ are identified on the edges of the \\ structure \\ - Particle matter appears as a valid \\ tracer of vertical velocities
}

Supporting Information:

- Supporting Information S1

- Figure S1

- Figure S2

Correspondence to:

L. Rousselet,

lrousselet@ucsd.edu

Citation:

Rousselet, L., Doglioli, A. M., de Verneil, A., Pietri, A., Della Penna, A., Berline, L., et al. (2019). Vertical motions and their effects on a biogeochemical tracer in a cyclonic structure finely observed in the Ligurian Sea. Journal of Geophysical Research: Oceans, 124, 3561-3574. https://doi.org/10.1029/ 2018JC014392

Received 24 JUL 2018 Accepted 12 APR 2019 Accepted article online 23 APR 2019 Published online 7 JUN 2019

(C)2019. American Geophysical Union. All Rights Reserved.

\section{Vertical Motions and Their Effects on a Biogeochemical Tracer in a Cyclonic Structure Finely Observed in the Ligurian Sea}

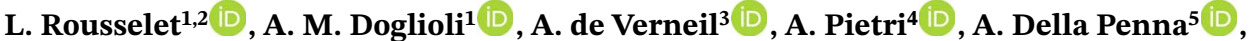 \\ L. Berline ${ }^{1}$ (D) , P. Marrec ${ }^{1,6}$ (D) , G. Grégori ${ }^{1}$, M. Thyssen ${ }^{1}$, F. Carlotti ${ }^{1}$, S. Barrillon ${ }^{1}$, F. Simon-Bot ${ }^{1}$, \\ M. Bonal ${ }^{7}$ (D) , F. d'Ovidio ${ }^{4}$, and A. Petrenko ${ }^{1}$ \\ ${ }^{1}$ Aix-Marseille Univ., Universiteé de Toulon, CNRS, IRD, MIO UM 110, Marseille, France, ${ }^{2}$ Now at Scripps Institution \\ of Oceanography, University of California, San Diego, CA, France, ${ }^{3}$ The Center for Prototype Climate Modeling, New \\ York University Abu Dhabi, Abu Dhabi, United Arab Emirates, ${ }^{4}$ Sorbonne Université, CNRS, IRD, MNHN, Laboratoire \\ d'Océanographie et du Climat: Expérimentations et Approches Numériques (LOCEAN-IPSL), Paris, France, ${ }^{5}$ Applied \\ Physics Laboratory, University of Washington, Seattle, WA, USA, ${ }^{6}$ Now at Graduate School of Oceanography, University \\ of Rhode Island, Narragansett, RI, USA, ${ }^{7}$ Laboratoire d'Écologie des Systèmes Aquatiques, Université Libre de \\ Bruxelles, Brussels, Belgium
}

\begin{abstract}
Vertical velocities can be estimated indirectly from in situ observations by theoretical frameworks like the $\omega$-equation. Direct measures of vertical exchanges are challenging due to their typically ephemeral spatiotemporal scales. In this study we address this problem with an adaptive sampling strategy coupling various biophysical instruments. We analyze the 3-D organization of a cyclonic mesoscale structure finely sampled during the Observing Submesoscale Coupling At High Resolution cruise in the Ligurian Sea during fall 2015. The observations, acquired with a moving vessel profiler, highlight a subsurface low-salinity layer $(\simeq 50 \mathrm{~m})$, as well as rising isopycnals, generated by geostrophic cyclonic circulation, in the structure's center. Reconstructed 3-D fields of density and horizontal velocities are used to estimate the vertical velocity field down to $250 \mathrm{~m}$ by applying the adiabatic QG $\omega$-equation, for the first time in this region. The vertical motions are characterized by multipolar patterns of downward and upward velocities on the edges of the structure and significantly smaller vertical velocities in its center. Both the 3-D distribution of particles ( the Synechococcus and Prochlorococcus abundances (cell per cubic meter) measured by flow cytometry are consistent with the 3-D velocity field. In particular, a secondary vertical recirculation is identified that upwells particles (from 250 to $100 \mathrm{~m}$ ) along isohalines to the structure's center. Besides demonstrating the effect of vertical patterns on biogeochemical distributions, this case study suggests to use particle matter as a tracer to assess physical dynamics.
\end{abstract}

\section{Introduction}

Located in the North-Western Mediterranean Sea, the Ligurian Sea is characterized by a regional counterclockwise circulation. This latter can be intensified due to specific atmospheric conditions and thus create a cyclonic gyre in the area (Astraldi \& Gasparini, 1994). The regional circulation is formed by the junction of both the surface Western Corsica Current and Eastern Corsica Current, in the vicinity of the Cap Corse to form the Northern Current (Figure 1), which then continues its way west toward the Strait of Gibraltar (Astraldi \& Gasparini, 1992; Millot, 1999; Millot \& Taupier-Letage, 2005). The Ligurian Sea is also mainly characterized by an oligotrophic regime except from fall to early spring when chlorophyll $a$ concentration (Chl $a$ in the following) can reach $1 \mathrm{mg} / \mathrm{m}^{3}$. An increase of primary production rate can also be caused by an intense biological activity generated along a frontal system that separates coastal and offshore waters in the regional circulation scheme (Goffart et al., 1995). Seasonal and/or peculiar events, such as gales of northwesterly wind (so-called Mistral), can also influence the phytoplankton community structure, and then the biological activity (Thyssen et al., 2014). The seasonal increase in Chl $a$, from fall to early spring, in this region benefits the entire marine food web including zooplankton, macrozooplankton, and cetaceans (Forcada et al., 1995; Gordon et al., 2000). Due to its biological importance, the Ligurian Sea became, in 


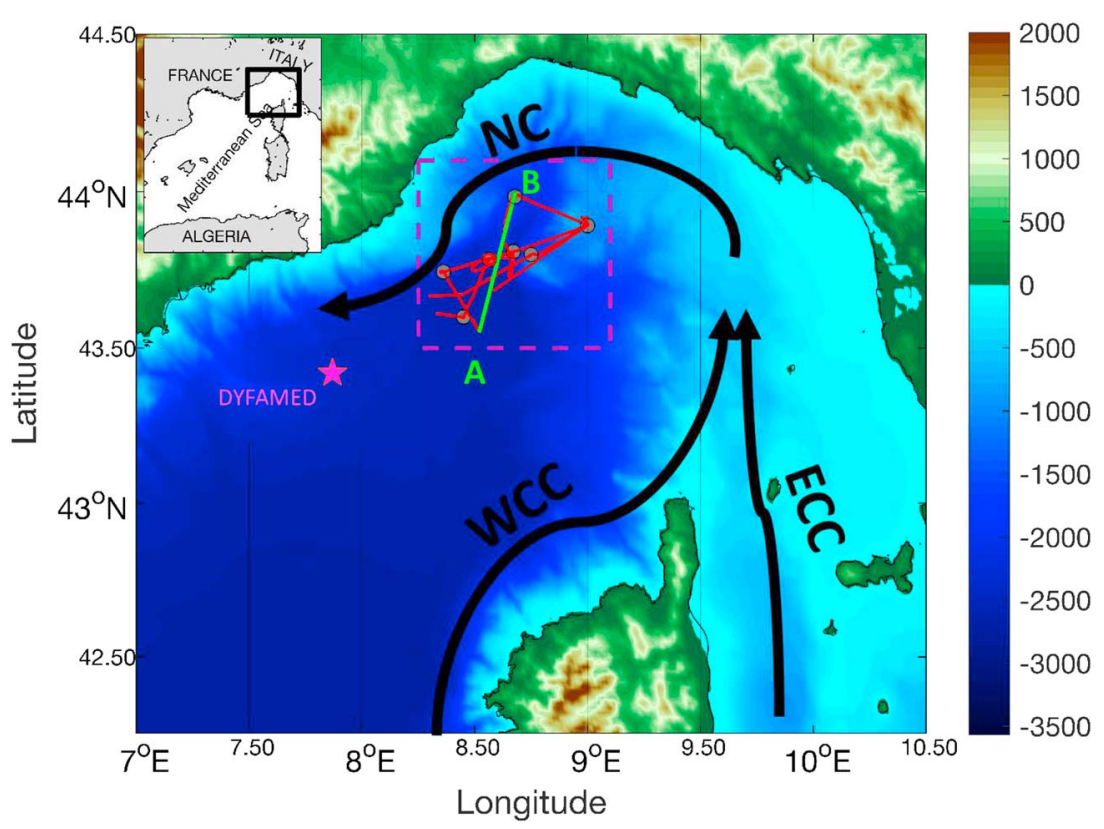

Figure 1. Bathymetry (m, color bar) and Ligurian Sea circulation scheme (WCC = Western Corsica Current; ECC $=$ Eastern Corsica Current; NC $=$ Northern Current). The positions of DYFAMED station and hydrological stations performed during Observing Submesoscale Coupling At High Resolution (OSCAHR) are shown by the magenta star and the gray black circled points, respectively. The route of the vessel during the second leg of the OSCAHR cruise is shown by the red line. The green segment figures the AB transect that almost entirely crossed the cyclonic circulation. The purple dashed square delimits the area defined as the OSCAHR cyclonic circulation location.

February 2002, an international sanctuary for Mediterranean marine mammals, PELAGOS (Notarbartolo-di Sciara et al., 2008).

The regional circulation and frontal system that regulate the physical and biological dynamics of the Ligurian Sea are nowadays well understood. However, the vertical exchanges, and the physical processes associated, that drive biogeochemical matter distribution and modulate biological activity (Mahadevan, 2016; McGillicuddy, 2016; Lévy et al., 2018) have been poorly explored in the Mediterranean Sea. To our knowledge, only Pascual et al. (2017) recently performed an experiment in the Alboran basin. The vertical motions, generated in mesoscale (or submesoscale) features, structures with space scales of the order of (or smaller than) the typical value of the Rossby radius in the Mediterranean Sea ( $10 \mathrm{~km}$; Grilli \& Pinardi, 1998; Pascual et al., 2004) can play a key role for primary production by supplying nutrients to the upper layers (Martin et al., 2001; Lévy et al., 2012). Different physical processes are known to cause vertical motions within mesoscale structures: deformations of the flow and spatial inhomogeneities (Giordani et al., 2006), eddy perturbation (Martin \& Richards, 2001; Nardelli, 2013; Pilo et al., 2018), linear Ekman pumping (McGillicuddy et al., 1998; Gaube et al., 2015), or eddy-wind interactions (McGillicuddy et al., 2007). However, the study of these vertical motions is still very challenging as those features, and their interactions with biogeochemistry are hard to sample (Mahadevan \& Tandon, 2006; Mahadevan, 2016; McGillicuddy, 2016) but also because direct measurements of vertical velocities are not yet possible.

The estimation of vertical velocities, and more specifically the estimation from in situ data, has become an important challenge to study fine-scale (e.g., spatial scales on the order of a few meters to a few kilometers) dynamics (Lévy et al., 2018). This diagnostic, based on in situ measures, requires specific high-resolution and well-shaped in situ samplings of the structure of interest to assess 3-D fields of density and horizontal velocity. Although different approaches were considered to diagnose vertical motions from the sampled density and horizontal velocities (Garabato et al., 2001; Nardelli et al., 2018; Viúdez et al., 1996), the most common approach is the Q-vector version of the $\omega$-equation implemented by Hoskins et al. (1978) for the atmosphere. This formulation estimates, in quasigeostrophic theory (QG $\omega$-equation), the ageostrophic vertical velocities that tend to restore the thermal wind balance destroyed by the geostrophic deformation field. The adiabatic QG $\omega$-equation was adapted by Tintoré et al. (1991) and Pollard and Regier (1992) to assess vertical velocities in oceanic mesoscale regions. 

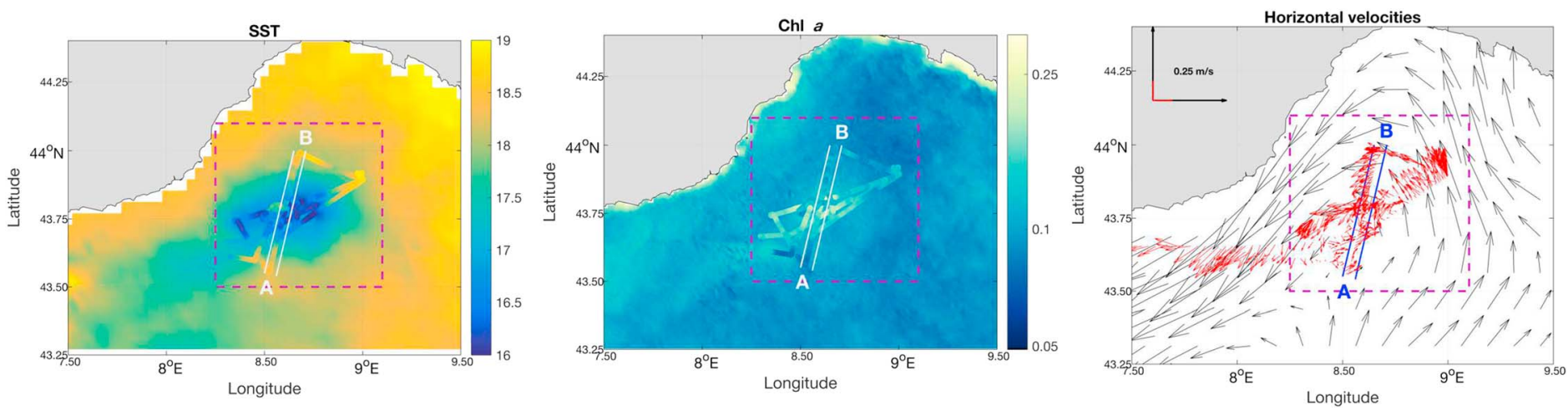

Figure 2. Left: pseudo-Lagrangian map of $\mathrm{SST}_{S a t}\left({ }^{\circ} \mathrm{C}\right.$, color bar) together with scatter points of $\mathrm{SST}_{t s g}\left({ }^{\circ} \mathrm{C}\right.$, color bar). Center: pseudo-Lagrangian map of $\mathrm{Chl}_{\text {Sat }} a$ (milligram per cubic meter, color bar) together with scatter points of $\mathrm{Chl}_{t s g} a$ derived from the TSG fluorimeter (milligram per cubic meter, color bar). Right: the 3-day mean of geostrophic currents derived from altimetry (AVISO) are displayed with black arrows as well as the horizontal components of the velocity measured by the acoustic Doppler current profiler (18.5-m depth, red arrows). The purple dashed square delimit the area defined as the Observing Submesoscale Coupling At High Resolution cyclonic circulation location. The white and blue lines delimit the AB transect. SST $=$ sea surface temperature.

In the present study, we propose to use the biophysical high-frequency sampling performed during the OSCAHR (Observing Submesoscale Coupling At High Resolution) cruise (Doglioli, 2015) to study the horizontal and vertical distribution of physical and biogeochemical variables within a cyclonic structure located in the Ligurian Sea. First, we characterize the flow and the hydrographic properties of the cyclonic structure both on the horizontal and vertical scales, using in situ high-frequency data sets (section 3.1). These latter stem from ThermoSalinoGraph (TSG), acoustic Doppler current profiler (ADCP), and moving vessel profiler (MVP) measurements of, respectively, temperature, salinity, and horizontal currents conducted during a Lagrangian survey that aimed to follow the cyclonic structure for 3 days. The reconstruction of the 3-D $(x, y, z)$ fields of density and horizontal velocities, from in situ observations, is performed in order to compute vertical velocities from the QG $\omega$-equation. The 3-D dynamics of the cyclonic structure are described in section 3.2. Moreover, the vertical velocities are matched with the distribution of particles (in the range $100 \mu \mathrm{m}$ to few centimeters) observed thanks to a laser optical plankton counter (LOPC mounted on the MVP; section 3.3). Our results are finally discussed in section 4 , and we use high-frequency cytometry measurements of phytoplankton abundances to evaluate the origins of particle distribution. Main conclusions are drawn in section 5 .

\section{Material and Methods}

\subsection{OSCAHR Sampling Strategy}

The present study focuses on the second leg of the OSCAHR cruise (Doglioli, 2015) that was performed in the Ligurian Sea onboard R/V Téthys II between 3 November 2015 and 6 November 2015 (Figure 1). This study is based on an adaptive strategy: Near-real-time data from satellite measurements (see sections 2.4) and numerical modeling were analyzed to identify features of interests. In this case, the SPASSO software (Software Package for an Adaptive Satellite-based Sampling for Ocean campaigns; http://www.mio.univ-amu. fr/SPASSO/; Doglioli et al., 2013; d'Ovidio et al., 2015; Petrenko et al., 2017) allowed for the identification of a cold and Chl $a$ enriched structure characterized by a cyclonic circulation (Figure 2). Then a Lagrangian in situ sampling of the structure was performed thanks to two different types of floats (1 SVPlike drifter anchored at 15-m depth and two CODE drifters anchored at 1-m depth) that were deployed at the estimated center of the structure $\left(8.65^{\circ} \mathrm{E}, 43.8^{\circ} \mathrm{N}\right)$ on 3 November 2015 . All three drifters depicted a global westward movement, of about $0.25^{\circ}$ in 2 days, of the structure (data not shown). The OSCAHR in situ sampling was performed in a range of $0.75^{\circ}$ in longitude ensuring that the cruise sampled the desired structure. Physical and biogeochemical parameters were measured with high frequency, both at the surface (corresponding to a few kilometer resolution) and on the vertical (few meters resolution), and are described in the following sections.

\subsection{Underway Measurements}

The sea surface temperature $\left(\mathrm{SST}_{t \mathrm{sg}},{ }^{\circ} \mathrm{C}\right)$ and Salinity $\left(\mathrm{SSS}_{t \mathrm{tg}}\right)$ were evaluated every minute all along the cruise route. The TSG, equipped with a SeaBird SBE21, was connected to a continuous surface water flow-through system that pumped seawater at 2-m depth. In the following, temperature and salinity will 
refer to absolute salinity and conservative temperature according to TEOS-10 standards (McDougall et al., 2012). Sea surface fluorescence was acquired with a Turner Designs fluorometer (10-AU-005-CE) and was converted into surface $\mathrm{Chl} a\left(\mathrm{Chl}_{t s g} a\right.$, milligram per cubic meter). Calibration and validation details of each underway surface measurements are available in Marrec et al. (2018).

Continuous measurements of horizontal velocities, with 8-m depth bins, were also recorded with a Shipboard-Accoustic Doppler Current Profiler (S-ADCP type RDI Ocean Sentinel $75 \mathrm{kHz}$ ). The depth range extends from $18.5 \mathrm{~m}$ down to $562.5 \mathrm{~m}$. S-ADCP data treatment was performed with the Matlab software Cascade V.7 (LOPS; Le Bot et al., 2011; http://wwz.ifremer.fr/lpo_eng/content/view/full/25928).

\subsection{High-Resolution Vertical Sampling}

Vertical profiles, at a spatial resolution of $\simeq 1 \mathrm{~km}$ (between four and six knots) were achieved with a MVP, MVP200 ODIM Brooke Ocean, during the nearly vertical free falls of the Multi Sensor Free Fall Fish type I equipped with a AML microCTD, a fluorimeter (unusable data), and a LOPC. A significant correlation between data collected at 5-m depth by the MVP and surface data from the TSG has been retrieved by Marrec et al. (2018). The LOPC recorded particle size and abundance distributions: It records the cross-sectional area of each particle passing through its laser beam (Herman et al., 2004; Herman \& Harvey, 2006) for a size range between $100 \mu \mathrm{m}$ and few centimeters. Associated with net tows, the living fraction of particles can be estimated (Espinasse et al., 2018). The sampling volume was estimated using the LOPC sampling tunnel surface multiplied by the depth increment estimated with the pressure sensor. Given the fish free-fall velocity of $\simeq 4 \mathrm{~m} / \mathrm{s}$ and the LOPC acquisition frequency $(2 \mathrm{~Hz}$ ), we binned the LOPC over 5 -m vertical bins. As the surface docking depth of the MVP fish was not constant, the first bin (0-7.5 m) was discarded from the analysis. The LOPC abundances were redistributed into log-scale size bins for easier analysis. Total abundance (e.g., abundance over the full LOPC size range) and abundance for a specific size range were analyzed. We thus have access to vertical profiles of total abundance of particles (particles per cubic meter) at almost each kilometer during the MVP transects.

\subsection{Satellite Products}

Satellite data from Copernicus Marine Environment Monitoring Service (http://marine.copernicus.eu/) are used for the adaptive strategy during the cruise as well as postcruise to extend the geographical and temporal information of $\mathrm{SST}_{S a t}$ and surface $\mathrm{Chl}_{S a t}$. Delayed-time L4 maps of $\mathrm{SST}_{\text {Sat }}$ (Mediterranean Sea - High Resolution L4 SST Reprocessed; Nardelli et al., 2013; Pisano et al., 2016) and $\mathrm{Chl}_{\text {Sat }}$ a (Mediterranean Sea Reprocessed Surface Chlorophyll Concentration from Multi Satellite observations) are retrieved for the period of the cruise, on regular grids of $0.04 \times 0.04^{\circ}$ resolution for $\mathrm{SST}_{\text {Sat }}$ and of $1 \times 1 \mathrm{~km}$ resolution for $\mathrm{Chl}_{\text {Sat }} a$. A correlation of 0.9 is shown between $\mathrm{SST}_{\text {Sat }}$ and $\mathrm{SST}_{t s g}$ allowing for confident use of this data set. For Chl $a$ concentration, the correlation between $\mathrm{Chl}_{\text {Sat }} a$ and $\mathrm{Chl}_{t s g} a$ is much worse (0.5). However, if the magnitude of the $\mathrm{Chl}_{\text {Sat }} a$ concentration differs, the patterns are quite similar between in situ and satellite estimations (Figure 2). Pseudo-Lagrangian-weighted mean $\mathrm{SST}_{\text {Sat }}$ and $\mathrm{Chl}_{\text {Sat }}$ a maps (de Verneil et al., 2017) are generated with satellite-derived data for the period of the cruise to avoid smoothing engendered by a basic mean. The weight for each pixel is calculated by using the normalized inverse squared distance from the pixel to the ship's daily mean position. Similar correlations are found with pseudo-Lagrangian maps.

\subsection{Vertical Velocities Estimation}

The 2-D (alongtrack, $\mathrm{z}$ ) data achieved during the OSCAHR cruise are used both to extend the vision of the data into a 3-D $(x, y, z)$ grid and to estimate vertical velocities. This approach consists in two steps: (1) An objective analysis is performed to compute 3-D maps of density and horizontal velocities; 2) the adiabatic QG $\omega$-equation is numerically solved by using the 3-D fields to infer vertical velocities.

The high-resolution density, velocity data, and particle distribution are interpolated onto a three-dimensional grid using objective analysis (Le Traon, 1990). Our application of this technique uses a set of functions to define the mean field with the statistics of the fluctuating field being anisotropic and Gaussian. Density and horizontal velocity correlation length scales are found to be 30 and $15 \mathrm{~km}$ in the $x$ and $y$ directions, respectively, with a structure orientation of $-22.5^{\circ}$ to maximize (minimize) the major (minor) axis decorrelation length scales, respectively. The noise-to-signal ration is assumed to be 0.05. The objective analysis was prescribed to fit the density data to an ellipse, whereas velocities are fit to linear functions in space (details in the supporting information). After objective analysis, density fields are constrained to be statically stable. Velocity fields are constrained to be in thermal wind balance by solving for a stream function that simultaneously incorporates geostrophic shear due to horizontal density 

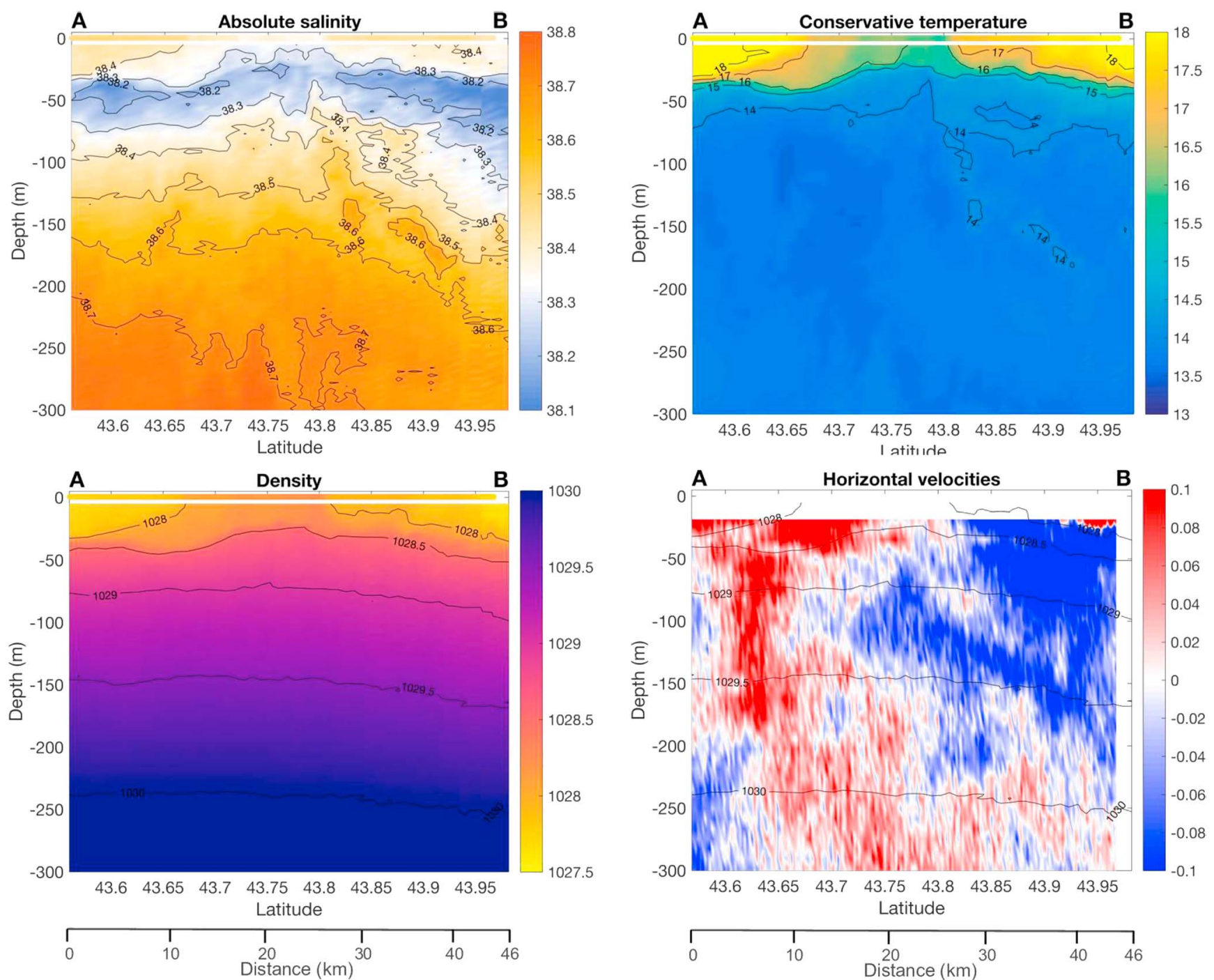

Figure 3. Vertical sections of absolute salinity (top left), conservative temperature ( ${ }^{\circ} \mathrm{C}$, top right), density (kilogram per cubic meter, bottom left), and cross-track velocity components (meter per second) along the northward AB transect from moving vessel profiler and acoustic Doppler current profiler (bottom right, + to the East and - to the West). At the surface, the corresponding measurements from the ThermoSalinoGraph are displayed with the respective color bar. Isolines of absolute salinity (intervals of 0.1$)$, conservative temperature $\left(1^{\circ}\right)$, and density $\left(0.5 \mathrm{~kg} / \mathrm{m}^{3}\right)$ are drawn with solid black lines.

gradients and minimizes misfit with the mapped velocity data, as shown in Rudnick (1996). These density and geostrophic velocity fields are used in estimating vertical velocities via the adiabatic QG $\omega$-equation. The final grid resolution is $0.8 \mathrm{~km} \mathrm{~N}-\mathrm{S} \times 1.2 \mathrm{~km} \mathrm{E-W}$ horizontally, and $3 \mathrm{~m}$ in the vertical (from 5- to 300-m depth). The final 3-D fields are checked to be in agreement with in situ measurements to ensure the reliability of the reconstructed fields (see Figure S1).

Adiabatic quasi-geostrophic vertical velocities (w) are generated by the tendency to compensate the thermal wind balance destruction due to geostrophic motions. These vertical motions can be estimated using a three-dimensional elliptic equation (1), involving the divergence of the $\mathbf{Q}$ vector (Hoskins et al., 1978) that is determined by horizontal derivatives of water density and horizontal velocity (equation 2; Pietri et al., 2013; Giordani et al., 2006).

$$
\begin{gathered}
\nabla^{2}\left(N^{2} \mathrm{w}\right)+f^{2} \frac{\partial^{2} \mathrm{w}}{\partial z^{2}}=2 \nabla \cdot \mathbf{Q}, \\
\text { with } \mathbf{Q}=\left(\mathbf{Q}_{\mathbf{1}}, \mathbf{Q}_{\mathbf{2}}\right)=\left(\frac{g}{\rho_{0}} \frac{\partial V_{g}}{\partial x} \cdot \nabla \rho \quad, \quad \frac{g}{\rho_{0}} \frac{\partial V_{g}}{\partial y} \cdot \nabla \rho\right) \text {, }
\end{gathered}
$$




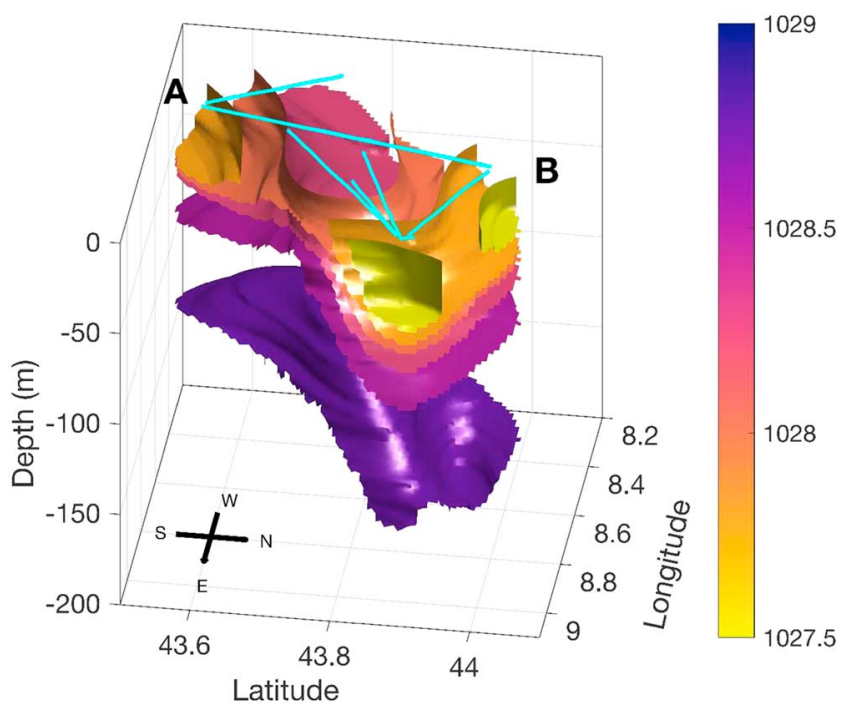

Figure 4. 3-D (longitude, latitude, and depth) isosurfaces of density (color bar) field reconstructed with the objective mapping method. The moving vessel profiler sections used for the reconstruction are schematized by the cyan lines, including the $\mathrm{AB}$ transect. with $V_{g}=\left(u_{g}, v_{g}\right)$ the geostrophic horizontal velocities, $\rho$ the density, $\rho_{0}$ a reference density, and $g$ the gravitational acceleration.

The limits of the domain should be considered cautiously. In the present study, we imposed Dirichlet $\mathrm{w}=0$ boundary conditions on a grid from 5- to 300-m depth. Neumann conditions can also be used, though for the $\omega$-equation this is not the popular choice (Rudnick, 1996; Thomas et al., 2010). The solution of this Poisson-type elliptic equation is computed using an iterative relaxation method.

\section{Results}

3.1. Hydrographic Observations of the Cyclonic Structure

TSG and ADCP high-frequency measurements provide a fine-scale sampling, at the surface, of the cyclonic structure (Figure 2). The core of the structure is characterized by relatively cold $\left(\mathrm{T} \simeq 16.5^{\circ} \mathrm{C}\right)$, fresh $(\mathrm{S} \simeq 38.2)$, and rich ( $\mathrm{Chl} a \simeq 0.25 \mathrm{mg} / \mathrm{m}^{3}$ ) surface waters. In contrast, the TSG measurements show warmer $\left(\mathrm{T} \simeq 19^{\circ} \mathrm{C}\right)$, saltier $(\mathrm{S} \simeq 38.5)$, and poor $(\mathrm{Chl} a$ $\simeq 0.1 \mathrm{mg} / \mathrm{m}^{3}$ ) waters on the edges of the structure. The direction of in situ surface currents (first bin at 18.5-m depth) are in good agreement with altimetry, although the intensity of satellite-derived current can differ from currents measured with the ADCP. The cyclonic structure and Northern Current are well represented on both data sets.

Figure 3 depicts the high-resolution vertical sections of salinity, temperature, resulting density, and horizontal currents measured during the Southwest to Northeast transect (from $43.55^{\circ} \mathrm{N}$ to $43.97^{\circ} \mathrm{N}$, green line on Figure 1) that almost crossed the structure entirely (hereafter referred as AB transect). The location of this transect is particularly suitable for the vertical characterization of both the core $\left(\simeq 43.7-43.85^{\circ} \mathrm{N}\right)$ and the edges of the cyclonic circulation. A subsurface layer, characterized by a low-salinity tongue $(\simeq 38.2)$, is observed at a depth about $50 \mathrm{~m}$ on the structure boundaries and about $30 \mathrm{~m}$ in its center. A low-salinity subsurface layer has already been observed close to our study area (Goutx et al., 2009; Marty et al., 2008) and seems to be rather typical of fall conditions (see modeled data in Figure S2). Below $100 \mathrm{~m}$, the salinity increases from 38.4 to 38.7 , following a classical salinity gradient toward depth. The deepening of isohalines

a)

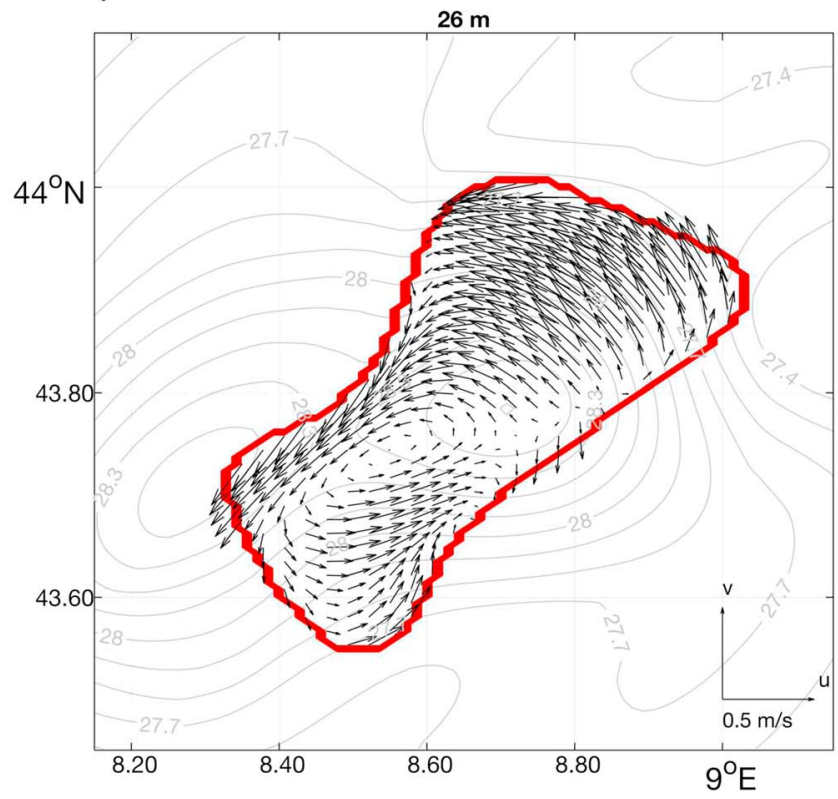

b)

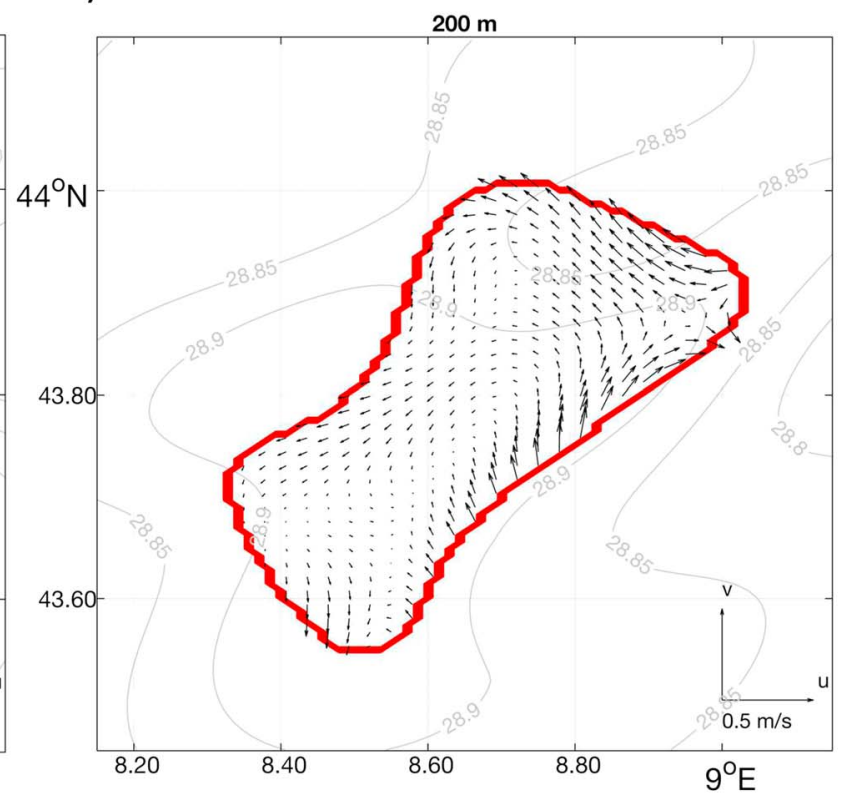

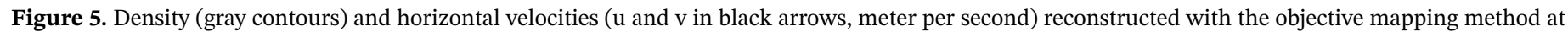
$26 \mathrm{~m}$ (a) and $200 \mathrm{~m}$ (b). Red line represents the contour of fields where the error on the objective mapping is $\leq 0.025$. 

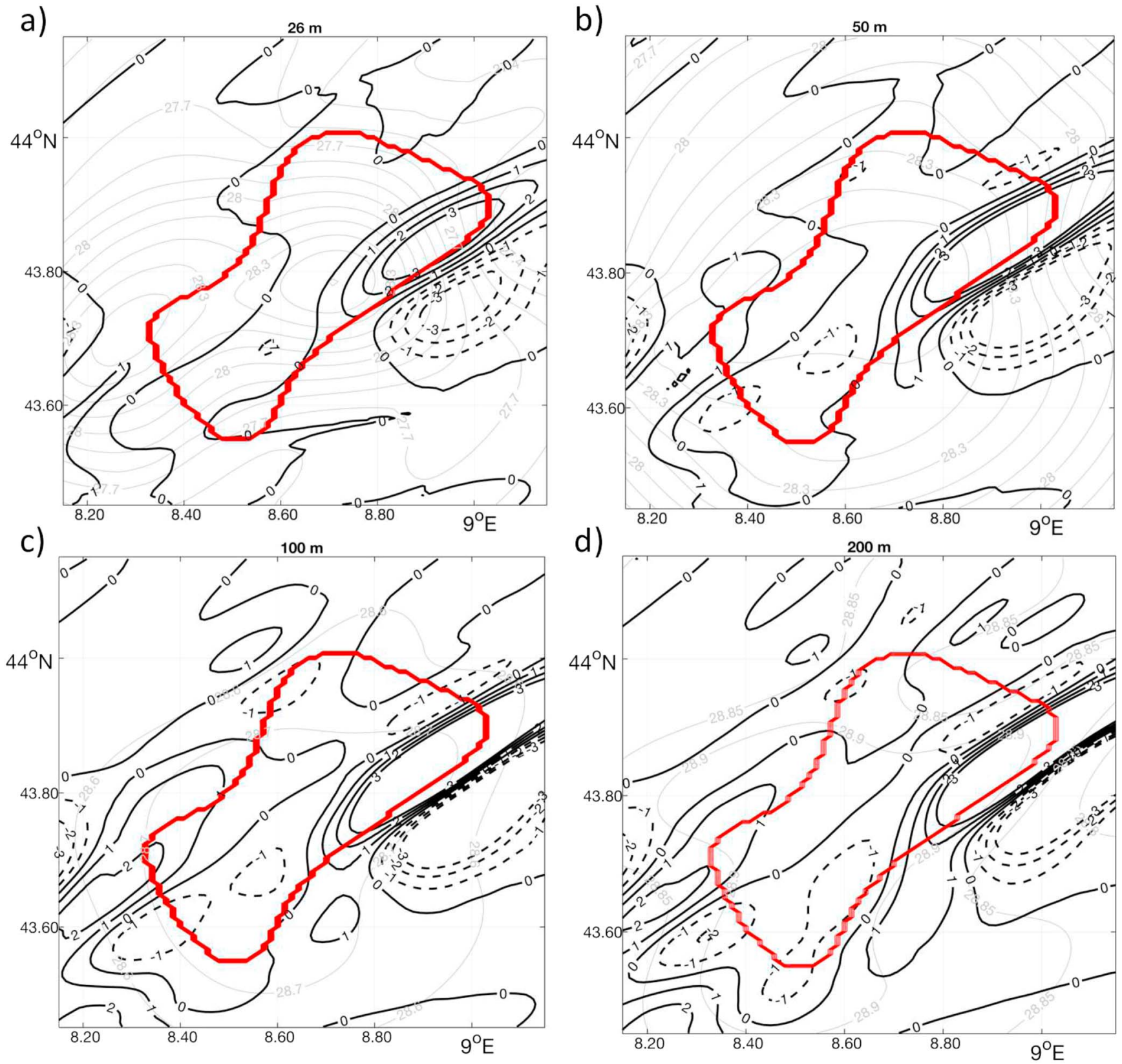

Figure 6. Vertical velocity $w$ (thick black contours, $1 \mathrm{e}^{-3} \mathrm{~m} / \mathrm{s}$ ) estimated from the $\omega$-equation at different depths: (a) $26 \mathrm{~m}$, (b) $50 \mathrm{~m}$, (c) $100 \mathrm{~m}$, and (d) $200 \mathrm{~m}$. Thin gray contours show the potential density anomaly $\sigma_{0}\left(\rho_{0}-1,000 \mathrm{~kg} / \mathrm{m}^{3}\right)$ from objective mapping. Red line represents the contour of fields where the error on the objective mapping is $\leq 0.025$.

at the end of the transect (starting around $43.85^{\circ} \mathrm{N}$ ) is probably indicative of a specific dynamic occurring at this location. The vertical temperature section shows a temperature gradient from $16-18^{\circ} \mathrm{C}$ at the surface to $13.5-14^{\circ} \mathrm{C}$ at $300 \mathrm{~m}$. A strong thermocline is visible at about $50-\mathrm{m}$ depth on the structure edges and between 20 and $30 \mathrm{~m}$ at the center of the structure. The density pattern reflects the observations on temperature and salinity sections: Isopycnals rise at the center of the structure, where the water is denser $(\simeq 1,028.25)$ than around $(\simeq 1,027.5)$, deepen on the edges and more importantly on the northern part of the $\mathrm{AB}$ transect $\left(\simeq 43.85^{\circ} \mathrm{N}\right)$. The $\mathrm{ADCP}$ section (Figure 3, bottom right) shows a clear cyclonic circulation with eastward velocities in the southern part of the transect (A side) and westward velocities in the northern part (B side). Horizontal currents are more intense on the edge of the cyclonic circulation $(0.1$ and $-0.1 \mathrm{~m} / \mathrm{s})$ and decrease around $43.85^{\circ} \mathrm{N}$ (between 0.02 and $-0.02 \mathrm{~m} / \mathrm{s}$ ). The weakest horizontal velocities are found where the 1,028 isopycnal reaches the surface that corresponds to the structure's center. ADCP data reveal that the 

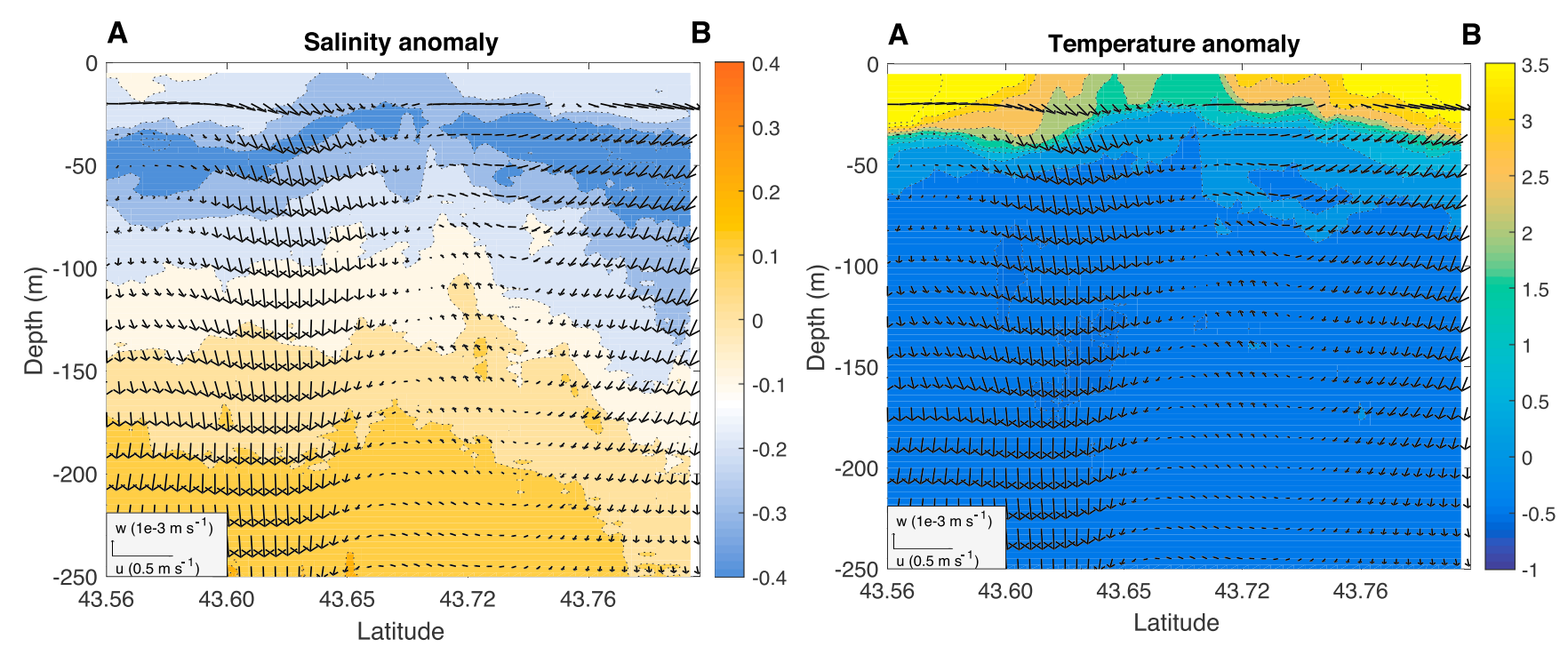

Figure 7. Vertical section of anomalies in salinity (color bar, left) and temperature (color bar, right) superimposed with along-track and vertical velocity components (meter per second, black arrows) along the $\mathrm{AB}$ transect.

structure extends to almost 200-m depth. Below that depth the velocities are mainly eastward. In situ data, both at the surface and on the vertical, describe a cyclonic structure extending down to $200 \mathrm{~m}$ with a typical upwelling process at its center that generates a rise of isopycnals.

\subsection{3-D Horizontal and Vertical Dynamics}

The objective mapping technique applied on all the sets of MVP and ADCP sections provide a full 3-D description of the cyclonic structure. Figure 4 displays the 3-D reconstructed isopycnal surfaces from 0 down to $200 \mathrm{~m}$. On this figure (and thereafter) the only field estimates considered are where the error is $\leq 0.025$. The two isopycnals surfacing and the doming of the structure is detectable on the 3-D figure. Figure 5 shows horizontal sections of density (gray contours) and horizontal velocities ( $u$ and v in black arrows) at 26 and $200 \mathrm{~m}$. The cyclonic circulation of the structure is noticeable from the surface down to $200 \mathrm{~m}$. Maximum horizontal velocities (in the order of $0.2 \mathrm{~m} / \mathrm{s}$ ) are detected at $26 \mathrm{~m}$ on the northern and western side of the structure. The structure center is estimated where horizontal velocities reach a minimum, around $8.6^{\circ} \mathrm{E}$ and $43.75^{\circ} \mathrm{N}$, which is located slightly west of the isopycnals dome. Indeed, at this depth the density varies from 28.5 near the center of the structure to 27.7 on the northern and southern part of the structure. We can also notice denser waters on the southwestern edge of the structure (28.3). At $200 \mathrm{~m}$ horizontal velocities are significantly smaller $(\simeq 0.05 \mathrm{~m} / \mathrm{s})$, corresponding to a less intense isopycnals rise. At this depth, the density field is more homogeneous (28.9).

To investigate in detail the vertical velocity field, we represent horizontal sections (Figure 6) at four depths of interest: (i) the 26-m level, which is just above the low-salinity tongue and far enough from the boundary level (surface) to avoid method inaccuracies; (ii) the 50-m level located within the low-salinity tongue; (iii) an intermediate level at $100 \mathrm{~m}$; and (iv) the 200-m level, below the low-salinity tongue where the signal of the cyclonic circulation is still detectable. At $26 \mathrm{~m}$ (Figure 6a), the vertical velocities are weak, and nearly 0 around the structure center, except on the northeastern boundary of the structure where we detect intense upward velocities (between $10^{-3}$ to $3.10^{-3} \mathrm{~m} / \mathrm{s}$ ). Those intense upward velocities extend down to $200 \mathrm{~m}$. The more the depth increase the more the vertical velocities distribution become complex. Indeed, multipolar patterns of downward and upward motions appear on the edges whereas the center of the structure remains influenced by weak vertical motions. Similar multipolar patterns, with velocity maximum on the periphery and significantly smaller vertical motions at the center, have already been observed inside mesoscale eddies (Barceló-Llull et al., 2017; Martin \& Richards, 2001; Nardelli, 2013) . As the vertical velocity distribution is 


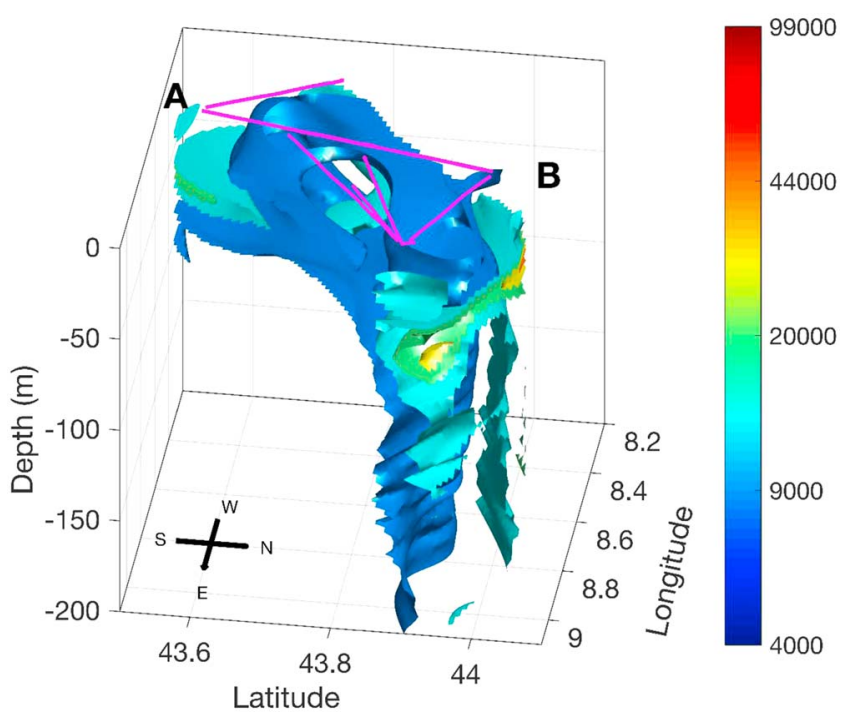

Figure 8. 3-D (longitude, latitude, and depth) isosurfaces of particle abundances (color bar, particle per cubic meter) reconstructed with the objective mapping method. The moving vessel profiler sections used for the reconstruction are drawn at the surface with the magenta lines. very complex within the structure, we decide to compare those patterns with biogeochemical tracers such as temperature, salinity, and particle abundances.

\subsection{Vertical Motions and Biogeochemical Tracers Distribution} The potential influence of vertical motions can be assessed by using the temperature, salinity, and particle abundance as tracers of the physical advection. Figure 7 represents, simultaneously, the 2-D in situ anomalies of salinity and temperature measured all along the $\mathrm{AB}$ transect, with the colocalized vertical and along-track components of the velocity. The anomalies are determined by the difference between the measure and the mean. The surface layer (from 0 to $100 \mathrm{~m}$ ) is fresher and warmer than the mean conditions in salinity and temperature along the $\mathrm{AB}$ transect down to $250 \mathrm{~m}$. By superimposing, in situ data sets and the reconstructed velocity field, we can notice that, in the southern part (A side), the intense downward velocities are associated with the weak downward transport of fresh waters represented by the little curvature of the salinity anomaly contours at $43.72^{\circ} \mathrm{N}$. When going north (toward B side), the contours of salinity anomaly deepen from 100 to $170 \mathrm{~m}$. This deepening is coupled with a secondary vertical recirculation cell (hereafter referred as secondary recirculation), between $43.80^{\circ} \mathrm{N}$ and $44^{\circ} \mathrm{N}$. Indeed, in the northern part of the transect (B side), negative salinity anomalies until $150 \mathrm{~m}$ (e.g., fresher waters are transported downward) follow intense downward velocities. Further south $\left(\simeq 43.80^{\circ} \mathrm{N}\right)$ the slope of salinity anomaly contours corresponds with weak, but not negligible, upward velocities. This recirculation is also visible near the surface layer (around $70 \mathrm{~m}$ ) with a peculiar and localized temperature anomaly. The horizontal and vertical velocities might thus be responsible for the mixing of subsurface fresh and cool waters with colder and saltier deeper waters. This vertical velocity pattern matches the salinity isolines deepening, identified in Figure 3.

The LOPC provides high-resolution distribution of particles along the AB transect. In the same way as density and horizontal velocities, the 3-D map of particle concentrations is reconstructed to study their distribution within the cyclonic circulation (Figure 8). The iso-concentration surfaces exhibit moderated particle concentrations near the surface $(\simeq 10,000$ particle per cubic meter) and high abundances of particles, associated with pycnocline, within the 50-m layer (between 50,000 and 100,000 particle per cubic meter). On the northern part of the circulation (B side), the particle abundances are rather homogeneous from the surface to $200 \mathrm{~m}$, except around the 50-m layer where the particle signal increase. On the southern part (A side), as the concentration of particles is very weak below $70 \mathrm{~m}$, they do not appear on the figure (abundances $\leq 4,000$ particles per cubic meter are not displayed). The northern vertical pattern is located where we identified upward (northeastern part) and intense downward (northwestern part) motions on the horizontal sections of vertical velocities (Figure 6).

Figure 9 (left panel) displays the particle vertical distribution along the AB transect, as well as the along-track and vertical components of the velocity. The particle abundance distribution shows latitudinal variations of the depth of the high concentration layer. From south (A) to north (B), this layer is located around $45 \mathrm{~m}$, drops to $50 \mathrm{~m}$ at $43.67^{\circ} \mathrm{N}$, and rises up to $40 \mathrm{~m}$ at the center and drops again around $50 \mathrm{~m}$ in the northern part. Each depth variation of this high-concentration layer is consistent with upward and downward corresponding velocities. As depicted on Figure 8, the northeastern edge of the circulation (B side, $\simeq 44^{\circ} \mathrm{N}$ ) is characterized by an homogeneous concentration of particles from 60 to $250 \mathrm{~m}$. This peculiar vertical distribution matches the downeastward velocities that decrease and even change sign (from downward to upward) when going south (from B to A side). The secondary recirculation, identified above, is also coupled with relatively significant concentrations of particles. The velocities at the center of this secondary recirculation are relatively weak and associated with a lower particle abundance. Another MVP transect was performed from $\mathrm{B}$ side toward the center of the AB transect, only $24 \mathrm{hr}$ before the AB sampling (right panel in Figure 9). This second snapshot shows the same vertical particle tongue associated with the secondary recirculation. The time interval between both transects gives informations on the temporal aspect of the dynamic: The upward vertical velocities existed for long enough to actually be able to drag a patch of particles upward. 

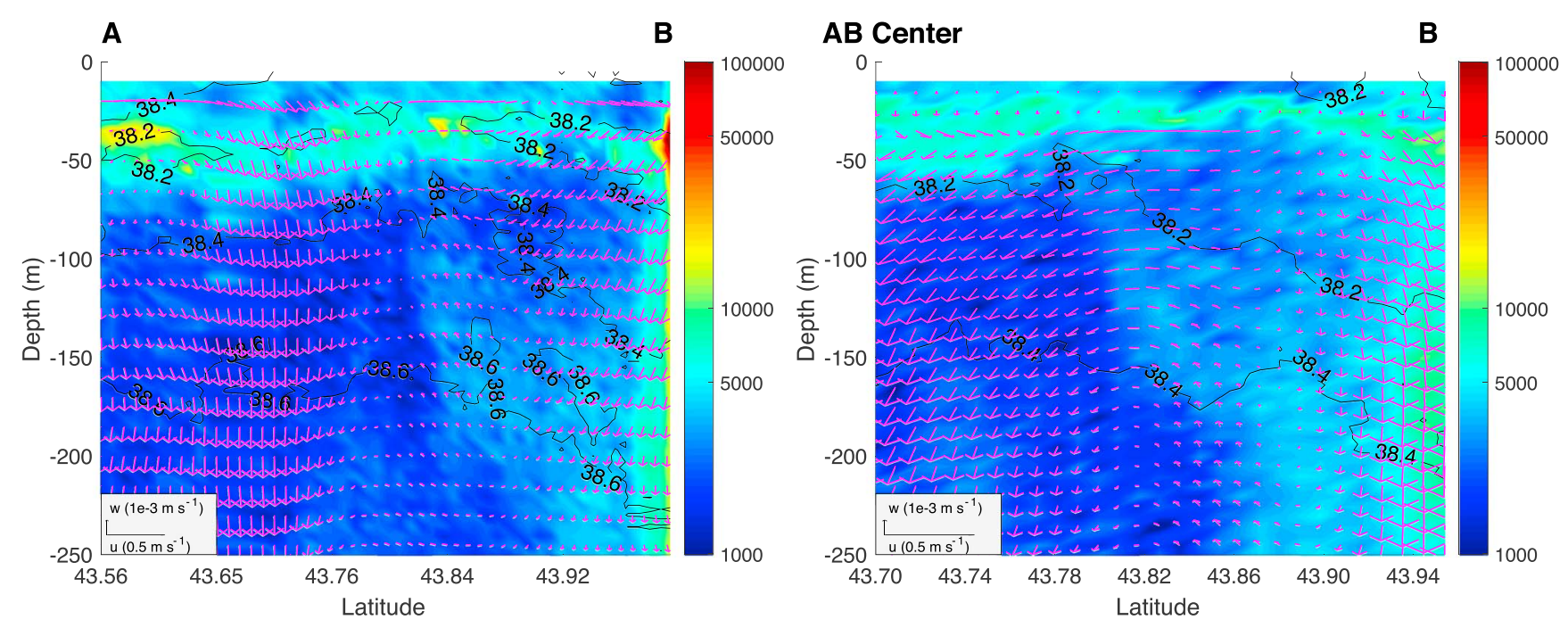

Figure 9. Vertical section of particle abundances (color bar, particle per cubic meter) superimposed with along-track and vertical velocity components (black arrows, meter per second) along the $\mathrm{AB}$ transect (4 November) and along the transect between $\mathrm{AB}$ center and $\mathrm{B}$ ( 5 November). Isocontours of salinity are represented with black lines (intervals of 0.2 ).

These observations suggest that, on the northern part of the structure, the vertical velocities probably strongly influence the vertical structure of the cyclone and also potentially drive the vertical distribution of the suspended particulate matter. The intense downward velocities, on A side, that do not seem to drive the same particle distribution response will be discussed in section 4.2.

\section{Discussion}

\subsection{Vertical Motions Sources and Uncertainties Estimations}

In the present study, we show ageostrophic vertical velocities estimated with the adiabatic version of the QG $\omega$-equation. However, the vertical motions inside the cyclonic structure of interest cannot be entirely explained with those estimations but are rather a combination of multiple processes that are not addressed in this study. Indeed, the vertical velocities can be strongly affected by surface turbulent mixing in the upper mixed layer (Nagai et al., 2006). Moreover, several previous studies also showed that the effect of the wind could not be neglected when estimating vertical motions, especially in the upper layer of the ocean (here 300 m; Barceló-Llull et al., 2017; Nagai et al., 2006). Marrec et al. (2018) already showed, using low-resolution wind estimates (WRF Weather Research and Forecasting model simulations and satellite scatterometer data), that the region underwent several wind events prior the cruise including one strong event on the first day of the cruise. Their Ekman pumping estimations were characterized by mean negative (e.g., upwelling) vertical velocities for about a month and maximum upward velocities of 3-4 m/day. Thus, both Ekman pumping and ageostrophic vertical motions, induced by the deformation of the flow, are likely to play an important role in driving the observed distributions inside the mesoscale cyclonic structure. The main doming of the isopycnals is probably due to the Ekman pumping induced by the strong wind blowing over the whole area whereas the fine-scale distribution of the particles along the deepening isopycnals (B side) can be explained by quasigeostrophic vertical motions.

In highly energetic mesoscale flows, typical vertical velocities are of the order $10^{-5} \mathrm{~m} / \mathrm{s}$ (between 1 and 10 m/day; Pollard \& Regier, 1990; Tintoré et al., 1991) although maximum vertical velocities obtained with the Q-vector $\omega$-equation can be as large as $10^{-3} \mathrm{~m} / \mathrm{s}$ (Allen \& Smeed, 1996). In the present study, the vertical velocities are of order $10^{-4} \mathrm{~m} / \mathrm{s}$ corresponding to a mean vertical flux of $130 \mathrm{~m} /$ day inside the cyclonic structure. These values are rather typical of vertical velocities estimated in submesoscale oceanic front (Mahadevan \& Tandon, 2006). Several studies have estimated typical vertical velocities of about $10 \mathrm{~m} /$ day within mesoscale structures (Barceló-Llull et al., 2017; Martin \& Richards, 2001; Nardelli et al., 2018). However, Nardelli (2013) has already calculated intense vertical velocities, larger than $100 \mathrm{~m} /$ day within a mesoscale eddy in the Agulhas Current, similarly to those estimated in our case study. Moreover, the adiabatic QG $\omega$-equation has shown consistent structures, at about 50-km scale, and a good agreement with 


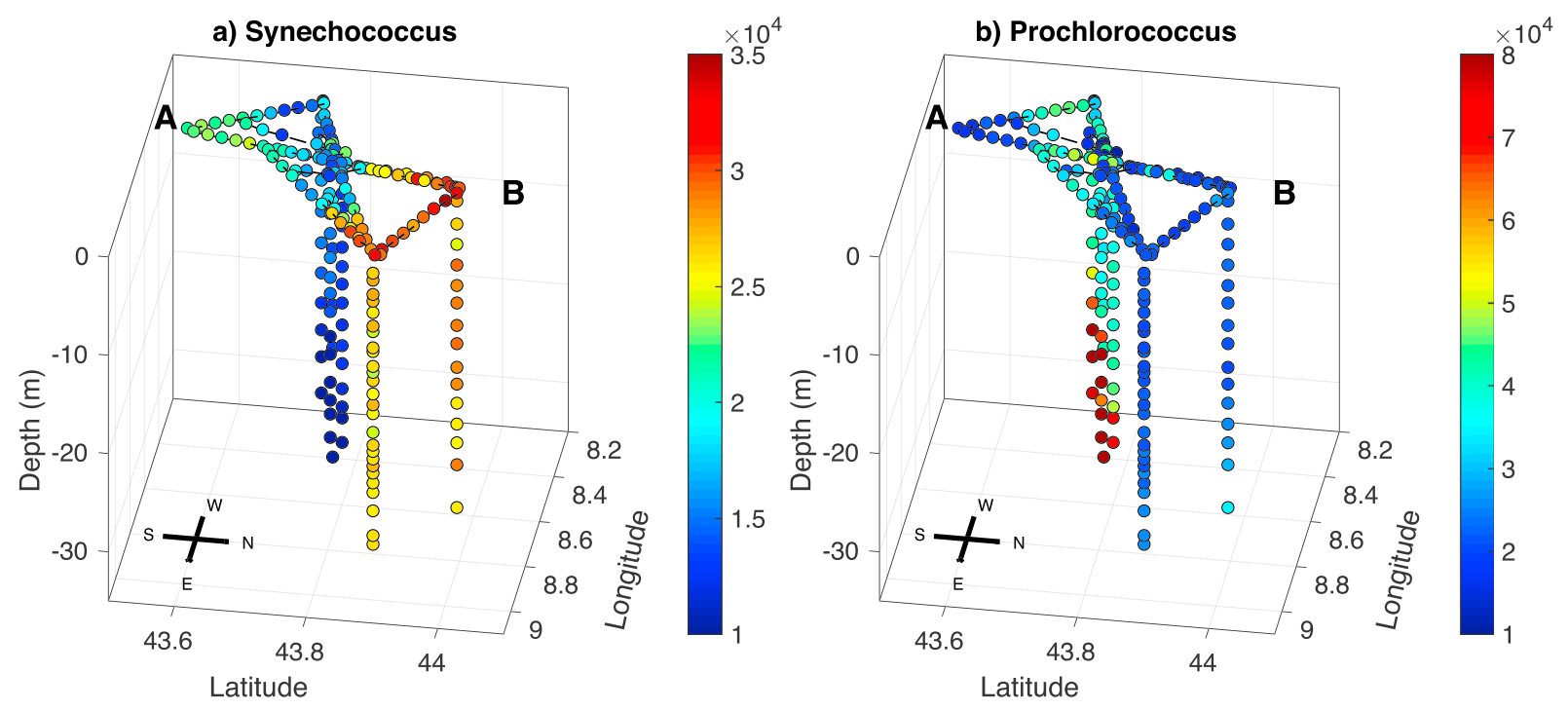

Figure 10. Synechococcus (a) and Prochlorococcus (b) abundances (cell per cubic meter) measured by flow cytometry.

the patterns of vertical velocities computed from primitive equation model outputs (Nardelli et al., 2012) although the intensities differ slightly from the modeled ones.

One source of error in the estimation of vertical velocities could be the sampling shape. Allen et al. (2001), using subsampling outputs of an ocean model, have reported that a combination of factors, such as the sampling shape and frequency as well as the in situ data set smoothing and asynopticity (direction of the ship related to the propagation of the perturbation flow) could lead to $85 \%$ errors in the estimation of net vertical heat flux. All studies that dealt with vertical velocities estimations from in situ observations have sampled fronts or eddies with a "radiator" shape sampling. Indeed, to our knowledge, it is the first time that a "butterfly"-type sampling is used in order to reconstruct 3-D fields and estimate vertical motions. At the time of the cruise, this shape of sampling route had been considered the best compromise between (i) to follow the track of the JASON3 satellite for validating altimetry measurements and (ii) to perform physical-biological coupled sampling of a cyclonic circulation. Otherwise, tide effects are negligible in this region of the microtidal Mediterranean Sea. Inertial currents have also not been observed in the buoy trajectories (data not shown). Thus, apart from the quasi-geostrophic balance assumption, the specific design of the OSCAHR cruise could be a source of error in the vertical velocities estimation. It could be tested with a high-resolution numerical model, but we consider such a work out of topic of the present study focused on in situ measurements.

\subsection{Particle Distribution: A Tracer for Advection}

Within the cyclonic structure, we have observed intense downward and lower upward velocities. This asymmetry is rather typical of $\Theta(1)$ Rossby-number dynamics with downwelling being more intense than upwelling (Mahadevan \& Tandon, 2006). On B side of the AB transect the vertical velocities seem to be associated with peculiar distributions of salinity and particles. Horizontal and ageostrophic vertical velocities have already been shown to shape the distribution of tracers or planktonic organisms horizontally (Dandonneau et al., 2003; d'Ovidio et al., 2010; Rousselet et al., 2018) or to advect nutrients to upper layers. In the present study, the vertical distribution of particles (around $43.85^{\circ} \mathrm{N}$ ) follows the isopycnals and, in particular, the salinity isolines, similarly to submesoscale vertical flux of nutrient (Mahadevan, 2016). The homogeneous vertical distribution on B side differs from the typical 1-D vertical profile of particle, which is an exponential decrease of abundance with depth. As a consequence, this distribution raises questions, also as it is associated with intense downward motions: Is the vertical dissemination due to the downwell of particles (1) or is it the signal of a different water mass enriched in particles (2)? The hypothesis 1 is realistic, considering that the particle signal is mostly in the size class $100-260 \mu \mathrm{m}$. Indeed, these particles can be considered as neutrally buoyant or slowly sinking ( $\simeq 2 \mathrm{~m} /$ day; Guidi et al., 2008) material and can easily be advected downward by the vertical velocity intensities estimated. Moreover, several studies have already reported cases of eddy-driven subduction of phytoplankton cells (Fielding et al., 2001; Guidi et al., 2012; 
Omand et al., 2015; Pollard \& Regier, 1990). Although the downward transport of particles can be possible, the hypothesis 1 seems unlikely if we consider (a) the intensity of the downward velocities and (b) the different particle signal associated with intense downward motions on A side. Indeed, a flux of $130 \mathrm{~m} /$ day would have probably removed all the particles from the upper layer. Moreover, velocities in the same range of magnitude are, on A side, only coupled with a localized slight deepening of isohalines and of the high abundance particle layer. We cannot exclude that, on A side, the downward motion has not lasted long enough to effectively observe a response of matter distribution, as we only have one snapshot on this side. This asymmetry in the vertical distribution of particles can also suggests that the observed patterns are remnants of passed events. Another probable assumption is that the high abundance of particles all along the vertical originates from a source of particle-enriched water mass that have been advected until the northern side of the cyclonic structure (hypothesis 2).

One opportunity to consider hypothesis 2 is to analyze the biogeochemical and biological composition of the water mass sampled on B side. The composition of the particle signal can give information on the origins of such distribution. The particle signal, which is intense in the deep chlorophyll maximum where phytoplankton abundance is expected to be higher, is mostly composed of unliving matter. The zooplankton fraction among these particles is estimated to $2-3 \%$ by concurrent net tows with $200-\mu \mathrm{m}$ mesh. This fraction is rather typical for the Mediterranean Sea. These particles may thus originate from terrigeneous matter or from primary production transformation (zooplankton fecal pellets and aggregates). Some informations on the phytoplankton content can provide a biological perspective in the horizontal and vertical dynamic of the cyclonic structure. Marrec et al. (2018) reported a heterogeneous spatial distribution of the two most abundant phytoplankton groups (Prochlorococcus and Synechococcus picocyanobacteria) observed across the cold core and warm boundary of the cyclonic structure (Figure 10). Similar patterns in terms of abundance of the main phytoplankton groups (e.g., Prochlorococcus and Synechococcus; Figure 10) were reported in the southern and northern warm boundary waters around the cold core. Prochlorococcus are more abundant in the cold core of the structure than in the warm boundaries, whereas Synechococcus exhibited the opposite distribution pattern. However, slightly higher abundances (between 3.5 and $410^{4}$ cell per cubic meter) of Synechococcus are observed in the northern part of the cyclonic structure where the particle signal increases. More interestingly, Marrec et al. (2018) highlighted the presence of a distinct population of Synechococcus, as defined by their fluorescence properties, in this northern part of the cyclonic structure. Based on these observations and on surface waters physical properties (warmer and fresher surface water in the northern part than in southern part of the cyclone), they suggested the presence of a specific warm water mass in the northern part of the structure, despite apparent similar biogeochemical properties, than waters from the southern part. This finding encompasses the asymmetry of the distribution of particles observed with the LOPC and also supports hypothesis 2 according to which a different water mass would be transported in the northern part of the cyclonic structure.

\section{Concluding Remarks}

In this study, we analyze a typical fall 3-D cyclonic structure sampled with high frequency during the OSCAHR cruise in the Ligurian Sea. The 2-D fine-scale vertical observations, achieved with a MVP, highlights a subsurface low-salinity layer that may originate from a combined inflow of both Western Corsica Current and Eastern Corsica Current subsurface low-salinity waters. The cyclonic structure geostrophically domed the isopycnals in the center of the structure causing the shallowing of the subsurface layer and enhanced biological production. The fine-scale sampling allows for the calculation of 3-D fields of density and horizontal velocities. These 3-D fields are then used to compute the vertical velocities from the adiabatic QG $\omega$-equation, for the first time in this region. The relatively weak vertical velocities at the center and the azimutal cells of downward and upward motions on the edges of the structure are in agreement with typical vertical velocities distribution inside a mesoscale structure. The ageostrophic vertical velocities are quite intense $\left(10^{-4} \mathrm{~m} / \mathrm{s}\right)$ and are coupled with upward motions generated by Ekman pumping. A secondary vertical recirculation is identified, on the northern edge of the structure, to upwell particles (from 250 to $100 \mathrm{~m}$ ) along isohalines to the center of the cyclone. The high abundance of nonliving particle in the northern edge is also strongly linked with higher abundance of a distinct population of Synechococcus. Those biogeochemical observations, coupled with physical investigation, suggest the transport of a distinct water mass to the northern edge of the structure. In this case study, we have used coupled biophysical in situ measurements 
to diagnose vertical motions and their biogeochemical signature. The particle matter distribution allowed here for the tracing of physical dynamics.

\section{Acknowledgments}

We thank Christophe Yohia and

Christel Pinazo for modeling outputs and their valuable help for SPASSO images analysis. We thank Nicole Garcia for Chl $a$ measurements. Special thanks go to the DT-INSU persons from la Seyne sur Mer, and in particular to Malika Oudia for her help in administration work and Céline Heyndrickx and Frédéric Le Moal for their technical support. Genavir and specifically Julien Fenouil are acknowledged for providing and assisting us with the MVP. MVP and the associated sensors were brought by IFREMER, LOPB, and now MIO with cofunding by the Centre Européen de Technologies Sous-Marine (CETSM Contrat de Projet Etat Région 2007-2013 en PACA) and the French ANR FOCEA (project ANR-09-CEXC-006-01 of M. Zhou and F. Carlotti). We also thank J. Thomas Farrar (MIT) for his suggestions on the cruise strategy. The OSCAHR cruise was supported by the MIO Axes Transverses program (AT-COUPLAGE), by FEDER fundings (PRECYM flow cytometry platform) and by the following projects: CHROME (PI M. Thyssen, funded by the Excellence Initiative of Aix-Marseille University A*MIDEX, a French Investissements d'Avenir program), SeaQUEST (PI O.Ross, funded by the UE FP7 people), AMICO (PI C. Pinazo, funded by Copernicus MEDDE French Ministery MDE), and BIOSWOT (PI F. d'Ovidio, funded by TOSCA/CNES). We also thank the captain and crew of the Téthys II research vessel. The project leading to this publication received funding from the European FEDER Fund under project 1166-39417. We thank the support of Labex OT-Med (ANR-11-LABX-0061) funded by the French government through the A*MIDEX project

(ANR-11-IDEX-0001-02). All data are available from authors.

\section{References}

Allen, J., \& Smeed, D. (1996). Potential vorticity and vertical velocity at the Iceland-Faeroes front. Journal of Physical Oceanography, 26(12), 2611-2634.

Allen, J., Smeed, D., Nurser, A., Zhang, J., \& Rixen, M. (2001). Diagnosis of vertical velocities with the QG omega equation: An examination of the errors due to sampling strategy. Deep-Sea Research I, 48(2), 315-346.

Astraldi, M., \& Gasparini, G. (1992). The seasonal characteristics of the circulation in the North Mediterranean Basin and their relationship with the atmospheric-climatic conditions. Journal of Geophysical Research, 97(C6), 9531-9540.

Astraldi, M., \& Gasparini, G. P. (1994). The Seasonal Characteristics of the Circulation in the Tyrrhenian Sea. Seasonal and Interannual Variability of the Western Mediterranean Sea, 46, 115-134.

Barceló-Llull, B., Pallàs-Sanz, E., Sangrà, P., Martínez-Marrero, A., Estrada-Allis, S. N., \& Arístegui, J. (2017). Ageostrophic secondary circulation in a subtropical intrathermocline Eddy. Journal of Physical Oceanography, 47(5), 1107-1123.

d'Ovidio, F., Della Penna, A., Trull, T. W., Nencioli, F., Pujol, M.-I., Rio, M.-H., et al. (2015). The biogeochemical structuring role of horizontal stirring: Lagrangian perspectives on iron delivery downstream of the Kerguelen plateau. Biogeosciences, 12(19), 5567-5581.

Dandonneau, Y., Vega, A., Loisel, H., Du Penhoat, Y., \& Menkes, C. (2003). Oceanic Rossby waves acting as a "hay rake" for ecosystem floating by-products. Science, 302(5650), 1548-1551.

de Verneil, A., Rousselet, L., Doglioli, A. M., Petrenko, A. A., \& Moutin, T. (2017). The fate of a southwest Pacific bloom: Gauging the impact of submesoscale vs. mesoscale circulation on biological gradients in the subtropics. Biogeosciences, 14(14), 3471-3486.

Doglioli, A. A. (2015). OSCAHR cruise, RV Téthys II, https://doi.org/10.17600/15008800

Doglioli, A. M., Nencioli, F., Petrenko, A. A., Rougier, G., Fuda, J.-L., \& Grima, N. (2013). A software package and hardware tools for in situ experiments in a Lagrangian reference frame. Journal of Atmospheric and Oceanic Technology, 30(8), $1940-1950$.

d'Ovidio, F., De Monte, S., Alvain, S., Dandonneau, Y., \& Lévy, M. (2010). Fluid dynamical niches of phytoplankton types. Proceedings of the National Academy of Sciences, 107(43), 18366-18370.

Espinasse, B., Basedow, S., Schultes, S., Zhou, M., Berline, L., \& Carlotti, F. (2018). Conditions for assessing zooplankton abundance with LOPC in coastal waters. Progress in Oceanography, 163, 260-270.

Fielding, S., Crisp, N., Allen, J., Hartman, M., Rabe, B., \& Roe, H. (2001). Mesoscale subduction at the Almeria-Oran front: Part 2. Biophysical interactions. Journal of Marine Systems, 30(3-4), 287-304.

Forcada, J., Di Sciara, G. N., \& Fabbri, F. (1995). Abundance of fin whales and striped dolphins summering in the Corso-Ligurian Basin. Mammalia, 59(1), 127-140.

Garabato, A. C. N., Leach, H., Allen, J. T., Pollard, R. T., \& Strass, V. H. (2001). Mesoscale subduction at the Antarctic Polar Front driven by baroclinic instability. Journal of Physical Oceanography, 31(8), 2087-2107.

Gaube, P., Chelton, D. B., Samelson, R. M., Schlax, M. G., \& O'Neill, L. W. (2015). Satellite observations of mesoscale eddy-induced Ekman pumping. Journal of Physical Oceanography, 45(1), 104-132.

Giordani, H., Prieur, L., \& Caniaux, G. (2006). Advanced insights into sources of vertical velocity in the ocean. Ocean Dynamics, 56(5-6), $513-524$.

Goffart, A., Hecq, J.-H., \& Prieur, L. (1995). Contrôle du phytoplancton du bassin Ligure par le front liguro-provençal (secteur Corse). Oceanologica Acta, 18, 329-342.

Gordon, J., Matthews, J., Panigada, S., Gannier, A., Borsani, J., \& Di Sciara, G. N. (2000). Distribution and relative abundance of striped dolphins, and distribution of sperm whales in the Ligurian Sea cetacean sanctuary: results from a collaboration using acoustic monitoring techniques. Journal of Cetacean Research and Management, 2(1), 27-36.

Goutx, M., Guigue, C., Aritio, D., Ghiglione, J., Pujo-Pay, M., Raybaud, V., et al. (2009). Short term summer to autumn variability of dissolved lipid classes in the Ligurian sea (NW Mediterranean). Biogeosciences, 6(7), 1229-1246.

Grilli, F., \& Pinardi, N. (1998). The computation of Rossby radii of deformation for the Mediterranean Sea. MTP news, 6(4), 4-5.

Guidi, L., Calil, P. H., Duhamel, S., Björkman, K. M., Doney, S. C., Jackson, G. A., et al. (2012). Does eddy-eddy interaction control surface phytoplankton distribution and carbon export in the North Pacific Subtropical Gyre? Journal of Geophysical Research, 117, G02024. https://doi.org/10.1029/2012JG001984

Guidi, L., Jackson, G. A., Stemmann, L., Miquel, J. C., Picheral, M., \& Gorsky, G. (2008). Relationship between particle size distribution and flux in the mesopelagic zone. Deep-Sea Research I, 55(10), 1364-1374.

Herman, A., Beanlands, B., \& Phillips, E. (2004). The next generation of optical plankton counter: The laser-OPC. Journal of Plankton Research, 26(10), 1135-1145.

Herman, A., \& Harvey, M. (2006). Application of normalized biomass size spectra to laser optical plankton counter net intercomparisons of zooplankton distributions. Journal of Geophysical Research, 111, C05S05. https://doi.org/10.1029/2005JC002948

Hoskins, B., Draghici, I., \& Davies, H. (1978). A new look at the $\omega$-equation. Quarterly Journal of the Royal Meteorological Society, 104(439), 31-38.

Le Bot, P., Kermabon, C., Lherminier, P., \& Gaillard, F. (2011). CASCADE V6. 1: Logiciel de validation et de visualisation des mesures ADCP de coque.

Le Traon, P.-Y. (1990). A method for optimal analysis of fields with spatially variable mean. Journal of Geophysical Research, 95(C8), $13,543-13,547$.

Lévy, M., Franks, P. J., \& Smith, K. S. (2018). The role of submesoscale currents in structuring marine ecosystems. Nature communications, 9(1), 4758.

Lévy, M., Iovino, D., Resplandy, L., Klein, P., Madec, G., Tréguier, A.-M., et al. (2012). Large-scale impacts of submesoscale dynamics on phytoplankton: Local and remote effects. Ocean Modelling, 43, 77-93.

Mahadevan, A. (2016). The impact of submesoscale physics on primary productivity of plankton. Annual review of marine science, 8 , 161-184.

Mahadevan, A., \& Tandon, A. (2006). An analysis of mechanisms for submesoscale vertical motion at ocean fronts. Ocean Modelling, 14(3), 241-256.

Marrec, P., Grégori, G., Doglioli, A. M., Dugenne, M., Della Penna, A., Bhairy, N., et al. (2018). Coupling physics and biogeochemistry thanks to high-resolution observations of the phytoplankton community structure in the northwestern Mediterranean Sea. Biogeosciences, 15(5), 1579 . 
Martin, A. P., \& Richards, K. J. (2001). Mechanisms for vertical nutrient transport within a North Atlantic mesoscale eddy. Deep Sea Research Part II: Topical Studies in Oceanography, 48(4-5), 757-773.

Martin, A. P., Richards, K. J., \& Fasham, M. J. (2001). Phytoplankton production and community structure in an unstable frontal region. Journal of Marine Systems, 28(1), 65-89.

Marty, J.-C., Garcia, N., \& Raimbault, P. (2008). Phytoplankton dynamics and primary production under late summer conditions in the NW Mediterranean Sea. Deep Sea Research Part I: Oceanographic Research Papers, 55(9), 1131-1149.

McDougall, T., Jackett, D., Millero, F., Pawlowicz, R., \& Barker, P. (2012). A global algorithm for estimating absolute salinity. Ocean Science, $8(6), 1123-1134$.

McGillicuddy, D. J. (2016). Mechanisms of physical-biological-biogeochemical interaction at the oceanic mesoscale. Annual Review of Marine Science, 8, 125-159.

McGillicuddy, D. J., Anderson, L. A., Bates, N. R., Bibby, T., Buesseler, K. O., Carlson, C. A., et al. (2007). Eddy/wind interactions stimulate extraordinary mid-ocean plankton blooms. Science, 316(5827), 1021-1026.

McGillicuddy, D. J. Jr, Robinson, A., Siegel, D., Jannasch, H., Johnson, R, Dickey, T., et al. (1998). Influence of mesoscale eddies on new production in the Sargasso Sea. Nature, 394(6690), 263.

Millot, C. (1999). Circulation in the western Mediterranean Sea. Journal of Marine Systems, 20(1-4), 423-442.

Millot, C., \& Taupier-Letage, I. (2005). Circulation in the Mediterranean Sea. In A. Saliot (Ed.), The Mediterranean Sea (Vol. 5K, pp. 29-66). Berlin, Heidelberg: Springer.

Nagai, T., Tandon, A., \& Rudnick, D. (2006). Two-dimensional ageostrophic secondary circulation at ocean fronts due to vertical mixing and large-scale deformation. Journal of Geophysical Research, 111, C09038. https://doi.org/10.1029/2005JC002964

Nardelli, B. B. (2013). Vortex waves and vertical motion in a mesoscale cyclonic eddy. Journal of Geophysical Research: Oceans, 118 , 5609-5624. https://doi.org/10.1002/jgrc.20345

Nardelli, B. B., Guinehut, S., Pascual, A., Drillet, Y., Ruiz, S., \& Mulet, S. (2012). Towards high resolution mapping of 3-D mesoscale dynamics from observations. Ocean Science, 8, 885-901.

Nardelli, B. B., Mulet, S, \& Iudicone, D. (2018). Three-dimensional ageostrophic motion and water mass subduction in the southern ocean. Journal of Geophysical Research: Oceans, 123, 1533-1562. https://doi.org/10.1002/2017JC013316

Nardelli, B., Tronconi, C., Pisano, A., \& Santoleri, R. (2013). High and ultra-high resolution processing of satellite sea surface temperature data over southern european seas in the framework of myocean project. Remote Sensing of Environment, 129, 1-16.

Notarbartolo-di Sciara, G., Agardy, T., Hyrenbach, D., Scovazzi, T., \& Van Klaveren, P. (2008). The Pelagos sanctuary for Mediterranean marine mammals. Aquatic Conservation: Marine and Freshwater Ecosystems, 18(4), 367-391.

Omand, M. M., DâĂŹAsaro, E. A., Lee, C. M., Perry, M. J., Briggs, N., Cetinić, I., \& Mahadevan, A. (2015). Eddy-driven subduction exports particulate organic carbon from the spring bloom. Science, 348(6231), 222-225.

Pascual, A., Gomis, D., Haney, R. L., \& Ruiz, S. (2004). A quasigeostrophic analysis of a meander in the Palamos Canyon: Vertical velocity, geopotential tendency, and a relocation technique. Journal of Physical Oceanography, 34(10), 2274-2287.

Pascual, A., Ruiz, S., Olita, A., Troupin, C., Claret, M., Casas, B., et al. (2017). A multiplatform experiment to unravel meso-and submesoscale processes in an intense front (alborex). Frontiers in Marine Science, 4, 39.

Petrenko, A. A., Doglioli, A. M., Nencioli, F., Kersalé, M., Hu, Z., \& d'Ovidio, F. (2017). A review of the LATEX project: Mesoscale to submesoscale processes in a coastal environment. Ocean Dynamics, 67(3-4), 513-533.

Pietri, A., Testor, P., Echevin, V., Chaigneau, A., Mortier, L., Eldin, G., \& Grados, C. (2013). Finescale vertical structure of the upwelling system off southern Peru as observed from glider data. Journal of Physical Oceanography, 43(3), 631-646.

Pilo, G. S., Oke, P. R., Coleman, R., Rykova, T., \& Ridgway, K. (2018). Patterns of vertical velocity induced by eddy distortion in an ocean model. Journal of Geophysical Research: Oceans, 123, 2274-2292. https://doi.org/10.1002/2017JC013298

Pisano, A., Nardelli, B., Tronconi, C., \& Santoleri, R. (2016). The new mediterranean optimally interpolated pathfinder AVHRR SST dataset (1982-2012). Remote Sensing of Environment, 176, 107-116.

Pollard, R., \& Regier, L. (1990). Large variations in potential vorticity at small spatial scale in the upper ocean. Nature, $348(6298), 227$.

Pollard, R., \& Regier, L. (1992). Vorticity and vertical circulation at an ocean front. Journal of Physical Oceanography, 22(6), 609-625.

Rousselet, L., De Verneil, A., Doglioli, A. M., Petrenko, A. A., Duhamel, S., Maes, C., \& Blanke, B. (2018). Large-to submesoscale surface circulation and its implications on biogeochemical/biological horizontal distributions during the OUTPACE cruise (southwest Pacific). Biogeosciences, 15(8), 2411.

Rudnick, D. L. (1996). Intensive surveys of the Azores Front: 2. Inferring the geostrophic and vertical velocity fields. Journal of Geophysical Research, 101(C7), 16,291-16,303.

Thomas, L. N., Lee, C. M., \& Yoshikawa, Y. (2010). The subpolar front of the Japan/East Sea. Part II: Inverse method for determining the frontal vertical circulation. Journal of Physical Oceanography, 40(1), 3-25.

Thyssen, M., Grégori, G. J., Grisoni, J.-M., Pedrotti, M. L., Mousseau, L., Artigas, L. F., et al. (2014). Onset of the spring bloom in the northwestern Mediterranean Sea: influence of environmental pulse events on the in situ hourly-scale dynamics of the phytoplankton community structure. Frontiers in microbiology, 5, 387.

Tintoré, J., Gomis, D., Alonso, S., \& Parrilla, G. (1991). Mesoscale dynamics and vertical motion in the Alboran Sea. Journal of Physical Oceanography, 21(6), 811-823.

Viúdez, Á., Haney, R. L., \& Tintoré, J. (1996). Circulation in the Alboran See as determined by quasi-synoptic hydrographic observations. Part II: Mesoscale ageostrophic motion diagnosed through density dynamical assimilation. Journal of Physical Oceanography, 26(5), 706-724. 